\title{
Monoamines in the pedal plexus of the land snail Megalobulimus oblongus (Gastropoda, Pulmonata)
}

\section{M.C. Faccioni-Heuser ${ }^{1}$, \\ D.M. Zancan ${ }^{2}$ \\ and M. Achaval ${ }^{1}$}

\author{
${ }^{1}$ Laboratório de Histofisiologia Comparada, Departamento de Ciências Morfológicas \\ and ${ }^{2}$ Departamento de Fisiologia, Instituto de Ciências Básicas da Saúde, \\ Universidade Federal do Rio Grande do Sul, Porto Alegre, RS, Brasil
}

\author{
Correspondence \\ M. Achaval \\ Laboratório de Histofisiologia \\ Comparada, Departamento de \\ Ciências Morfológicas, ICBS, UFRGS \\ Rua Sarmento Leite, 500 \\ 90050-170 Porto Alegre, RS \\ Brasil \\ Fax: +55-51-3316-3092 \\ E-mail: achaval@ufrgs.br
}

Research supported by FINEP

(No. 66.91.0509.0) and FAPERGS.

Received May 30, 2003

Accepted April 13, 2004

\begin{abstract}
In molluscs, the number of peripheral neurons far exceeds those found in the central nervous system. Although previous studies on the morphology of the peripheral nervous system exist, details of its organization remain unknown. Moreover, the foot of the terrestrial species has been studied less than that of the aquatic species. As this knowledge is essential for our experimental model, the pulmonate gastropod Megalobulimus oblongus, the aim of the present study was to investigate monoamines in the pedal plexus of this snail using two procedures: glyoxylic acid histofluorescence to identify monoaminergic structures, and the unlabeled antibody peroxidase anti-peroxidase method using antiserum to detect the serotonergic component of the plexus. Adult land snails weighing 48-80 g, obtained from the counties of Barra do Ribeiro and Charqueadas (RS, Brazil), were utilized. Monoaminergic fibers were detected throughout the pedal musculature. Blue fluorescence (catecholamines, probably dopamine) was observed in nerve branches, pedal and subepithelial plexuses, and in the pedal muscle cells. Yellow fluorescence (serotonin) was only observed in thick nerves and in muscle cells. However, when immunohistochemical methods were used, serotonergic fibers were detected in the pedal nerve branches, the pedal and subepithelial plexuses, the basal and lateral zones of the ventral integument epithelial cells, in the pedal ganglion neurons and beneath the ventral epithelium. These findings suggest catecholaminergic and serotonergic involvement in locomotion and modulation of both the pedal ganglion interneurons and sensory information. Knowledge of monoaminergic distribution in this snail's foot is important for understanding the pharmacological control of reflexive responses and locomotive behavior.
\end{abstract}

\section{Introduction}

In many invertebrates, especially in molluscs, the number of peripheral neurons can far exceed the number of neurons in the central
Key words

- Pedal plexus

- Catecholamines

- Serotonin

- Glyoxylic acid

- Immunohistochemistry

- Gastropod nervous system $(1,2)$. The foot is one of the most innervated areas in molluscs. The peripheral nervous system of the foot includes a pedal plexus, which is involved in locomotion, body movement and sensory function $(1,2)$. 
A high degree of structural organization has been described in the epithelial and muscular areas of the foot sole in Megalobulimus oblongus (3). The nerves from pedal ganglia give rise to small nerves that branch out to form the pedal plexus. This plexus consists of a nerve meshwork with ganglionic clusters located among the pedal muscle fibers. A similar organization has been described in other gastropods, such as Helix aspersa (4) and Ereminia ehrenbergi (5).

The distribution of neurotransmitters in the pedal plexus of some aquatic molluscs has been described. Neurotransmitters such as acetylcholine, dopamine and serotonin (5HT), diverse neuropeptides such as substance $\mathrm{P}$ and calcitonin gene-related peptide have been identified $(3,6,7)$. There is some disagreement regarding the presence of monoaminergic or peptidergic neuronal somata in the foot (8).

Among invertebrates, the most common catecholamine is dopamine, while adrenaline and noradrenaline are rare (6). In gastropods, dopamine is also the principal catecholamine and there is no evidence that the neurons are capable of synthesizing other catecholamines $(6,9)$. In a pharmacological review of rhythmic behaviors such as locomotion or breathing, the modulatory role of 5-HT is noteworthy in the control of locomotion $(8,10)$ and feeding (11-13), while dopamine has been reported to play a role in breathing (14). In addition, the modulatory role of 5-HT in aversive behavior $(10,15)$ has also been documented (16).

Most of the available knowledge concerning control of locomotion behavior comes from studies of aquatic gastropod species (ciliary gliding or swimming gastropods). However, terrestrial molluscs, which use waves of pedal muscular contraction for crawling, have been studied less (17).

One of the most difficult problems in neuroscience is the functional identification of the neurons involved in the networks underlying certain behavior, specially the modulatory and premotor interneuron cells. A detailed analysis of the structure and chemical nature of the neuronal circuits is a necessary prerequisite of neurophysiological studies. The usefulness of unique properties of molluscan nervous system for neurobiological research is widely recognized. The involvement of the serotonergic and dopaminergic neuronal networks in aversive, feeding, locomotive, and respiratory behavior has been described in other gastropods.

Given the absence of studies on the distribution of monoaminergic systems in the peripheral nervous system of terrestrial gastropods and the importance of this knowledge for our experimental model, M. oblongus, the aim of this study was to investigate monoamines in the pedal plexus of this snail using the glyoxylic acid fluorescence procedure and immunohistochemistry to detect 5-HT.

\section{Material and Methods}

Adult land snails, M. oblongus - Müller 1774, weighing 48-80 g were obtained from the counties of Barra do Ribeiro and Charqueadas (RS, Brazil) over a period of one year. The animals were kept in a screened terrarium, subjected to a controlled 12-h light/dark cycle and temperature $\left(20-25^{\circ} \mathrm{C}\right)$ and fed lettuce and water ad libitum.

\section{Histofluorescent method}

The histofluorescence method of De La Torre and Surgeon (18), with some modifications (19), was used to detect monoamines. Briefly, 23 snails were anesthetized by immersion in a menthol-saturated physiological solution $(29.5 \mathrm{mM} \mathrm{NaCl}, 2.4 \mathrm{mM} \mathrm{KCl}$, $6.0 \mathrm{mM} \mathrm{CaCl}_{2}$ ) for $30 \mathrm{~min}$. The foot musculature was dissected out and samples of the anterior, medial and posterior regions of the pedal muscle were obtained (20). The tissue fragments were frozen and horizontally or transversely sectioned $(75 \mu \mathrm{m})$ with a cry- 
ostat (Leitz Digital 1702) and picked up on glass slides. The sections were incubated in a solution containing $2 \%$ glyoxylic acid, 0.2 $\mathrm{M}$ sucrose and $0.236 \mathrm{M}$ monobasic potassium phosphate diluted in distilled water at $\mathrm{pH} 7.4$ for 3-5 min. The incubation in this solution and the subsequent steps were performed according to the method of Salimova and colleagues (21). The sections were examined with a Nikon fluorescence microscope, Optiphot-2, fitted with a V-2A filter block (BA450 barrier filter and EX 380-425 excitation filter), giving blue fluorescence to catecholamine fluorophores and yellow fluorescence to indole-reactive products.

Two control procedures were performed. In the first, 5 snails were injected into the anterior part of the foot (22) with $30 \mu \mathrm{g} / \mathrm{g}$ reserpine phosphate (Ciba) dissolved in a snail saline solution. The animals were kept at room temperature and after 3 days were processed as previously described. In the second, glyoxylic acid was omitted from the reaction solution used for sections from the pedal muscle.

\section{Immunohistochemistry}

This study was performed on 8 animals. Two snails were injected intramuscularly with $10 \mathrm{mg} / \mathrm{g} 0.1 \%$ colchicine (Enila Laboratory) (23) $48 \mathrm{~h}$ before muscle removal. The animals were then anesthetized in a mentholsaturated physiological solution and samples from the anterior, medial and posterior regions of the pedal muscle (20) were obtained and fixed in a fresh solution containing $4 \%$ (v/v) paraformaldehyde in $0.1 \mathrm{M}$ sodium phosphate buffer, $\mathrm{pH} 7.4$, at room temperature for $4 \mathrm{~h}$. The samples were then cryoprotected in a $30 \%$ sucrose solution in $0.1 \mathrm{M}$ sodium phosphate buffer, $\mathrm{pH} 7.4$, at $4^{\circ} \mathrm{C}$ with continuous stirring until they moved to the bottom of the container. After freezing, transverse sections $(50 \mu \mathrm{m})$ were obtained with a cryostat (Leitz). Sections were rinsed in phosphate-buffered saline (PBS) and pro- cessed for 5-HT immunohistochemistry by the unlabeled antibody peroxidase-antiperoxidase procedure (24). The sections were pretreated with $10 \%$ methanol diluted in $3 \%$ hydrogen peroxide for $30 \mathrm{~min}$, carefully washed and blocked with 3\% normal goat antiserum in PBS containing 0.4\% Triton$\mathrm{X} 100$ for $30 \mathrm{~min}$. The free-floating sections were incubated with a polyclonal antiserum raised in rabbits against 5-HT (Sigma) diluted 1:2000 in PBS-Triton X100 with continuous shaking for $48 \mathrm{~h}$ at $4^{\circ} \mathrm{C}$. The sections were washed in PBS and incubated with antirabbit IgG (1:50; Sigma) for $2 \mathrm{~h}$ at room temperature. The sections were washed in PBS and incubated with a rabbit peroxidaseantiperoxidase antibody (Sigma) diluted 1:500 for $2 \mathrm{~h}$ at room temperature. In order to develop the immunohistochemical reaction, the sections were treated in a medium containing $0.06 \% 3,3$ '-diaminobenzidine tetrahydrochloride (Sigma) for $10 \mathrm{~min}$ at room temperature and then in the same solution containing $1 \mu \mathrm{l} 3 \% \mathrm{H}_{2} \mathrm{O}_{2}$ per $\mathrm{ml}$ for $10 \mathrm{~min}$. For control, sections from the different regions of the pedal muscle were routinely processed by omitting the primary antibody.

\section{Results}

The histochemical glyoxylic acid method labeled monoaminergic fibers of varying diameters as well as the pedal plexus, located along the pedal muscle of the foot of $M$. oblongus. Both the same strong blue fluorescence of the catecholamines and the intense or pale yellow fluorescence characteristic of 5-HT were observed throughout the pedal muscle (Figure 1a,b). The 5-HT fibers quickly faded when exposed to ultraviolet light. Along the pedal muscle, deep orange or brownish auto-fluorescent elements were also detected. This auto-fluorescence remained even when glyoxylic acid was omitted from the solution or when the animals were submitted to reserpine phosphate treatment.

In the horizontal sections, monoaminer- 

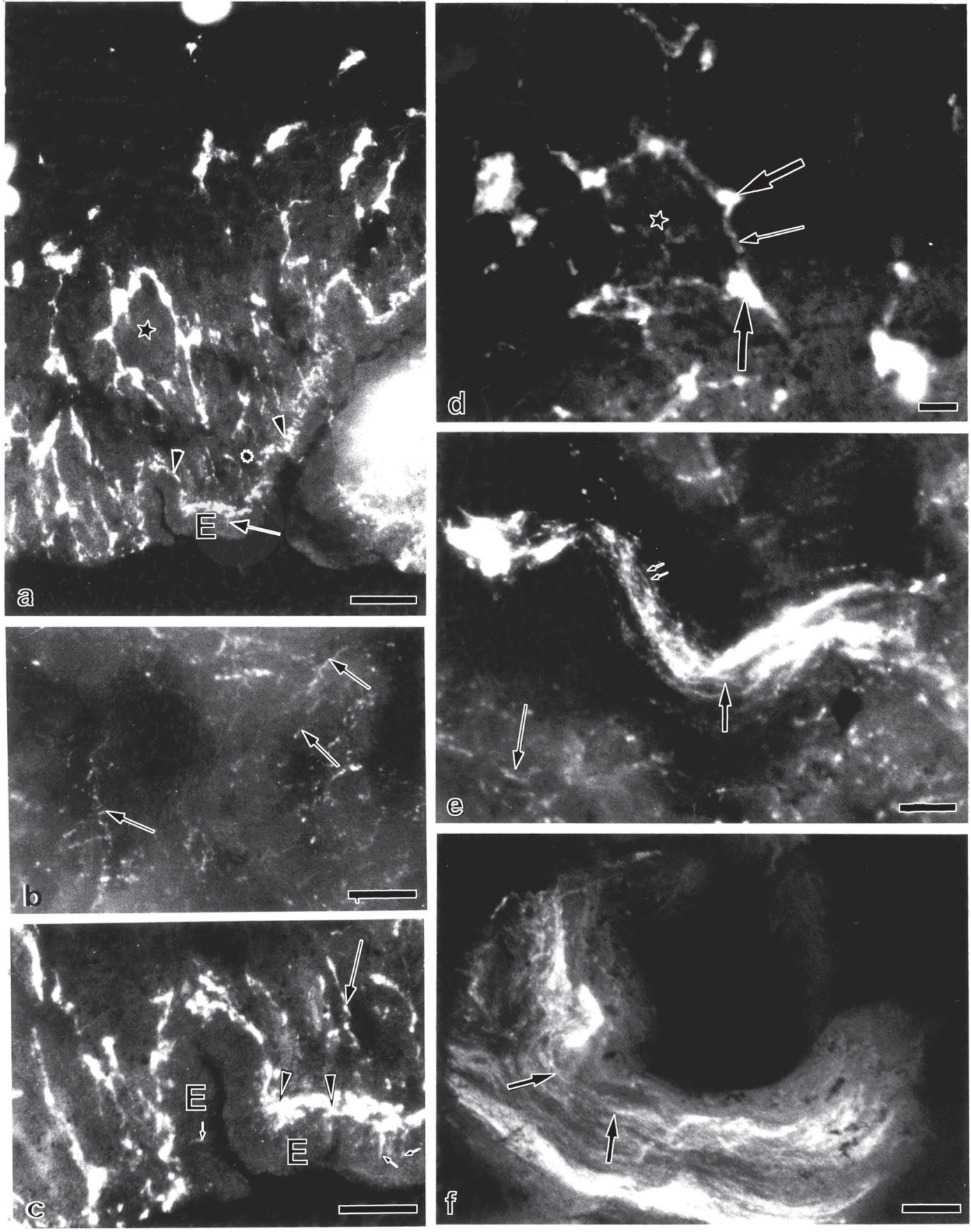

Figure 1. Fluorescent micrographs of the ventral aspect of Megalobulimus oblongus showing catecholamine (CA) and 5-hydroxytryptamine (5-HT) fluorescence in the pedal plexus. a, Note a dense mesh of CA-labeled fibers (arrowheads) against the ventral epithelium (E) and a loose CA network in the middle region of the pedal muscle that corresponds to the pedal plexus (star). From the subepithelial plexus (asterisk) some neuronal distal processes separated and penetrated between the epithelial cells (thin arrow). b. Section from the middle region of the pedal muscle showing 5-HT fluorescent varicose axons (arrows). c , Detail from a. Note the intense CA fluorescent subepithelial cells (arrowheads) from which some processes (thin arrow) penetrate between the epithelial cells (E). $d$, Detail of the pedal plexus (star). Observe CA fluorescence in ganglia (arrows) and in nerves that form the mesh (small arrow). e, Note nerves longitudinally sectioned with CA (arrow) and 5-HT (double arrow) fluorescent axons. Observe 5-HT fluorescent axons (thin arrow) in another nerve. $f$, A nerve over the muscle cells with CA fluorescent fibers (arrows). Bars: $a=100 \mu m ; b, e, f=20$ $\mu \mathrm{m} ; \mathrm{c}, \mathrm{d}=50 \mu \mathrm{m}$ 
gic fibers of varying diameters were found along the full extent of the foot of M. oblongus. The fluorescence found in these fibers was catecholamine. 5-HT varicose fibers as well as catecholamine ganglia were observed in the anterior, middle and posterior regions of the foot. In the middle region, thick nerves showing both catecholamine and 5-HT were observed between the muscle fascicles (Figure 1e,f). In the same section, a large number of 5-HT varicose fibers were also demonstrable. They were located over and parallel to the muscle fascicles, forming a delicate mesh (Figure 1b).

In horizontal sections of the most ventral regions, catecholamine fibers also occurred in all the zones of the foot. The catecholamine fibers formed a subepithelial reticule of fine interlinked fibers (Figure 1a,c). In these sections the 5-HT varicose fibers were not detected, probably as a result of being masked by the intense blue of the numerous catecholamine fibers. Catecholamine was detected in the form of a close woven mesh beneath this subepithelial reticule. This mesh was composed of catecholamine fibers and small nerve ganglia. In the intermediate regions, the catecholamine mesh of fibers was looser and the dimensions of the positive ganglia and fibers were greater than those in the ventral regions. In the middle region of the foot muscle, a loose mesh of nerve fibers formed the monoaminergic plexus and the ganglia were larger than those previously mentioned.

In transverse sections, it was possible to observe that the catecholamine nerve plexus was located in the middle and ventral regions of the pedal muscle, while in the dorsal region the catecholamine fibers were not detected. The 5-HT varicose fibers were best observed in the middle regions of the pedal muscle.

The ventral region of the anterior, middle and posterior regions of the pedal muscle exhibited a dense mesh of catecholamine fibers (described above) linked to the ventral epithelium. The intertwining of the nerve fibers and the ganglia could be clearly seen, forming a monoaminergic nerve plexus that corresponds to the pedal plexus (Figure 1a,d). Throughout the length of the ventral pedal musculature, $40 \mu \mathrm{m}$ from the ventral surface, an intense catecholamine reaction was seen, taking the form of an 8-10 $\mu$ m layer that bordered the epithelial basal region, forming the subepithelial plexus. Large numbers of fine axons originated from this plexus, penetrating between the epithelial cells (Figure $1 \mathrm{a}, \mathrm{c})$

The ganglia of the pedal plexus showed an intense catecholamine reaction in the neuropilar region, taking the form of either a dense network of fibers or sparse fine fibers with varicosities. Catecholamine axons were identified either entering or emerging from the ganglia. However, it was impossible to follow the trajectory of the axons within the ganglia because of the intense fluorescence of the neuropilar region. Catecholamine varicose fibers were also observed surrounding negative neuronal somata. Small catecholamine neuronal somata $(3 \mu \mathrm{m}$ in nuclear diameter) were identified in some of the ganglia of the pedal plexus. Few 5-HT fibers were seen in the neuropil because, as with the fibers of the plexus, they were probably masked by the intense catecholamine fluorescence of this region (Figure 2).

The distribution of 5-HT immunoreactive fibers was more easily observed in the sections of the foot of $M$. oblongus submitted to the immunohistochemical procedure for 5 HT detection. A 5-HT immunoreactive nerve network was found in the ventral regions of the anterior, middle and posterior zones of the foot, similar to that previously described for monoamines using the glyoxylic acid procedure (Figure 3). Intense 5-HT immunoreactive was detected in the nerve fibers and ganglia of the pedal plexus as well as in the region adjoining the ventral epithelium. Many of these immunoreactive fibers in the ganglia had not been identified using the 
Figure 2. Fluorescent micrographs of sections through ganglia and nerves of the pedal plexus of Megalobulimus oblongus. $a, b$ and $c$, Note the tightly clustered (asterisks) fluorescent fibers in the neuropilar region. Catecholamine (CA) fluorescent axons (arrowheads) entering or exiting the ganglia. Observe 5HT (double arrow) and CA (arrow) fluorescent fibers in the nerve fascicles. The ganglion in $b$ presents some CA varicosities surrounding negative neuronal bodies (small arrows). A ganglion in $c$ displaying a $\mathrm{CA}$ fluorescent neuronal soma (small arrow). Bars: a-c $=20 \mu \mathrm{m}$. glyoxylic acid method.

In the middle and ventral regions of the pedal muscle, a 5-HT immunoreactive nerve plexus was identified and a large number of 5-HT immunoreactive varicose axons were detected in the muscle cells (Figure 3b). In some cases these axons were several micrometers in length and ran parallel to the muscle cells (Figure 3a,b). No labeled plexus was found in the dorsal region. However, some thin nerves and 5-HT immunoreactive varicosities were detected in this region.
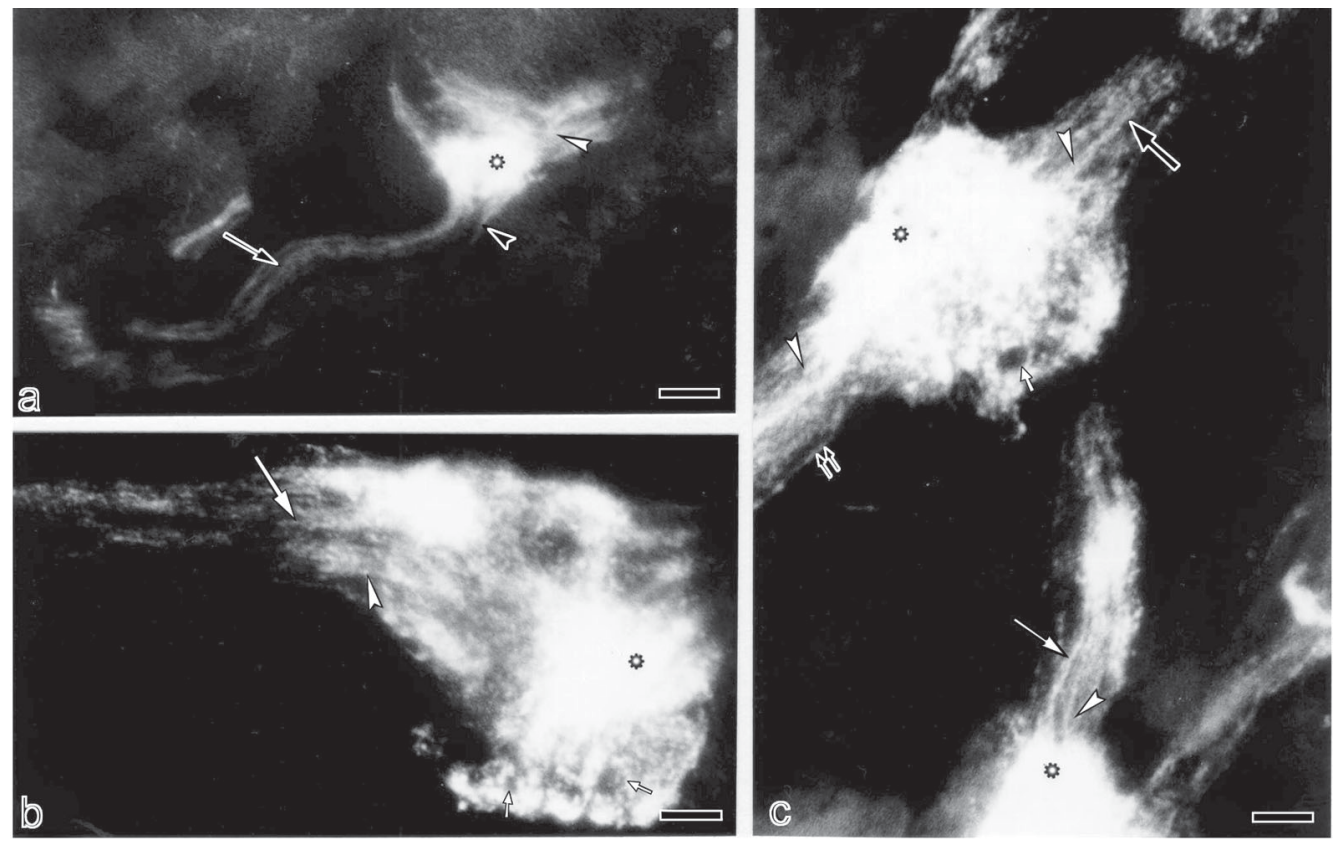

Figure 3. Photomicrographs of transverse sections of the ventral region of the pedal muscle of Megalobulimus oblongus showing 5-hydroxytryptamine (5-HT) immunoreactivity. a, Positive immunoreactivity in nerve fibers (arrows) and in some ganglia (arrowheads) of the pedal plexus. $b$, Detail from the pedal muscle. Note 5-HT immunoreactive nerves (arrowheads) and single varicose axons (arrows) over the muscle cells. $c$, Detail from the ventral aspect of the foot, showing 5HT immunoreactive varicose axons (arrowheads) of the subepithelial plexus and in other larger fibers (arrow). $\mathrm{E}=$ ventral epithelium. Bars: $\mathrm{a}=100 \mu \mathrm{m}, \mathrm{b}$ $=50 \mu \mathrm{m}, \mathrm{c}=20 \mu \mathrm{m}$.
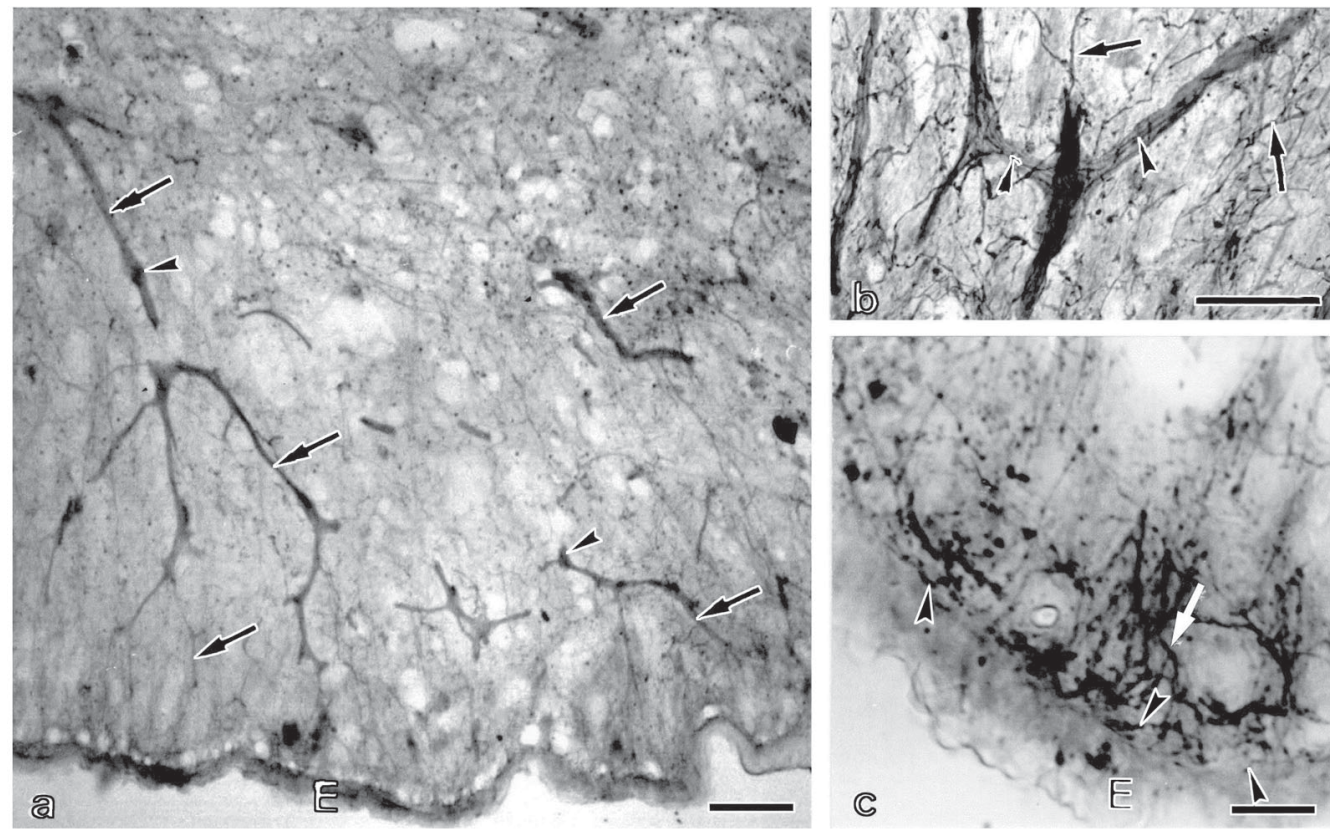
A dense arborization of 5HT immunoreactive fibers was seen in the subepithelial regions. These fibers originated in the pedal plexus and fanned out towards the basal region of the ventral integument epithelium, where they formed a delicate 5-HT immunoreactive nerve plexus, distributed throughout the middle and ventral regions of the muscle. In some cases 5-HT immunoreactive fibers extended between the epithelial cells of the ventral integument, reaching the apical region of the epithelium (Figure 3a,b).

Neuropilar areas of 5-HT immunoreactive were found in the pedal plexus ganglia. The immunoreactive fibers of the plexus nerves penetrated the ganglia (Figure 4). Some fibers emitted branches within the neuropil (Figure 4a,b), others terminated, emitting varicose branches that wrapped around neuronal somata (Figure 4c), while still others passed through the ganglia without emitting branches. Some 5-HT immunoreactive neuronal somata were identified in the ganglia of the pedal plexus following treatment with colchicine (Figure 4d). In treated animals, 5-HT immunoreactive single neurons were also located 100 to $150 \mu \mathrm{m}$ from the ventral epithelium. Other serotonergic neurons were found adjacent to the integument and their distal processes trav-
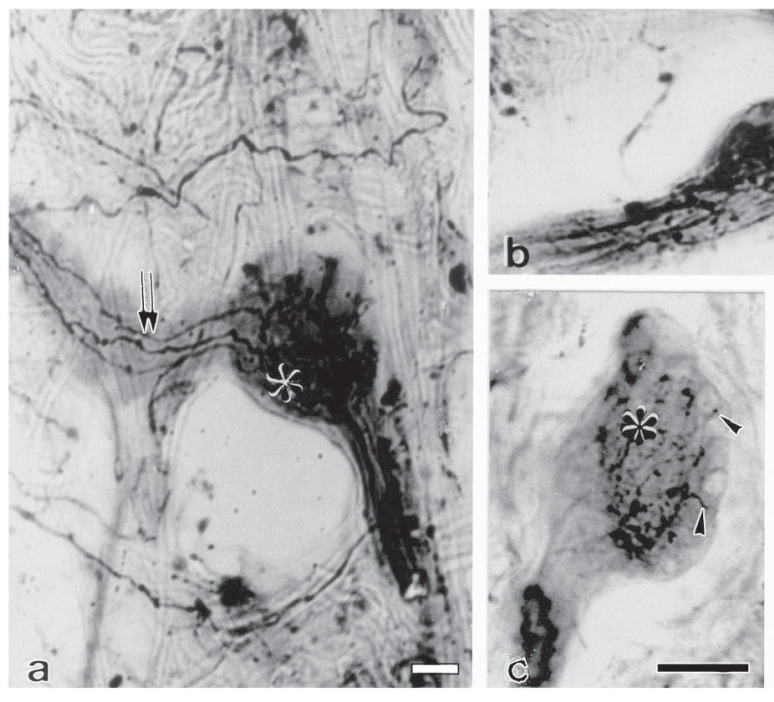
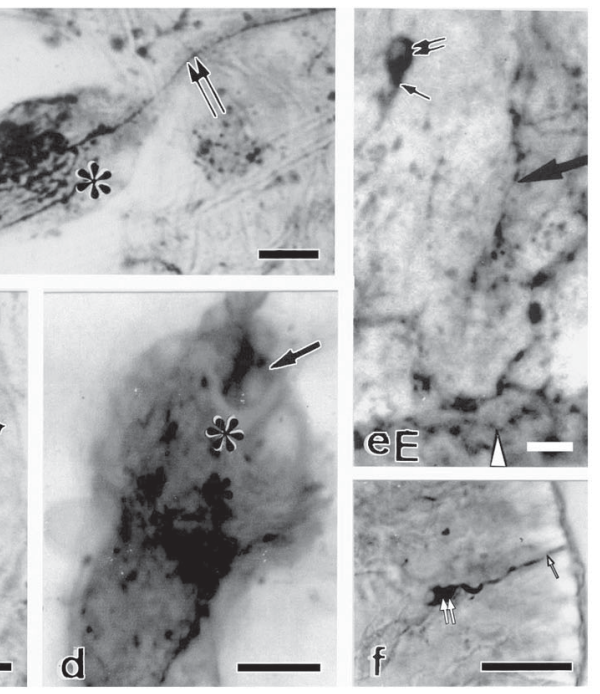

eled between the epithelial cells (Figure 4e,f).

\section{Discussion}

Monoaminergic fibers were identified throughout the pedal plexus of M. oblongus. Catecholamine nerves of varying diameters were labeled in the medial region of the pedal muscle, throughout the pedal plexus and in the subepithelial plexus. Catecholamines were also detected in the ganglia, in the epithelial basal zone and between the lateral regions of epithelial cells. However, 5-HT fibers were only found in thick nerves of the medial region of the pedal muscle, distributed as a delicate mesh of fibers over the muscle cells. The detection of labeled serotonergic fibers in the pedal and subepithelial plexuses, as well as in the basal and lateral zones of the epithelial cells was made possible by using the immunohistochemical procedure.

Similar monoaminergic fluorescence was detected in the pedal plexus of Helix pomatia, but in ganglionic neurons no fluorescence was observed (4). In addition, similar findings were reported for all foot regions of Mytilus galloprovincialis, but only monoaminergic neurons near the epithelial zone were labeled. In this mussel, the monoaminergic fluorescence was correlated with the pres-

Figure 4. Photomicrographs of foot section of Megalobulimus oblongus. $a$ and $b$, Detail from the pedal plexus showing a ganglion with an intensely 5 hydroxytryptamine $(5-\mathrm{HT})$ immunoreactive neuropil (asterisks). Observe 5-HT immunoreactive fibers (double arrows) that enter or exit the ganglion. $c$, Ganglion showing positive axons (arrowheads) surrounding negative neuronal somata. d, Ganglion displaying a 5-HT immunoreactive neuronal soma (arrow). e, Transverse section from ventral region of the foot. Positive varicose axon (arrow) above the muscle cells and in the subepithelial plexus (arrowhead) over the epithelium (E). Note a serotonergic neuronal soma (double arrow) and its process (thin arrow). $f$, Ventral epithelium of foot. Observe a 5-HT immunoreactive neuronal body (double arrow) and its distal process (arrow) traveling between two epithelial cells. Bars: $a-f=$ $20 \mu \mathrm{m}$. 
ence of dopamine and 5-HT in the terminal nerve electron-dense vesicles of the foot (25). In M. oblongus, catecholamine containing subepithelial plexus and axons between the epithelial cells were identified; these axons probable belong to neurons located in the subepithelial plexus. However, during the postembryonic development of the foot of Lymnaea stagnalis, numerous catecholamine fibers were found concentrated beneath the ciliated epithelium. Short processes originating from the subepithelial plexus neurons penetrated the epithelium and long processes extended to the pedal nerves (2). The differences between these findings may be due to the fact that specimens were sacrificed during different life stages and in Lymnaea the pedal and subepithelial plexuses were not completely developed. On the other hand, the numerous labeled neurons beneath the epithelium in Lymnaea were not identified in M. oblongus. But in both species, catecholamine free terminals were located between the ventral epithelium. The catecholamine-containing cellular processes, whether or not they form a plexus, probably mediate mechanoand/or chemosensation reception $(1,26)$.

What is the origin of these catecholamine processes in the pedal muscle of M. oblongus? All the fibers enter or exit the foot through the pedal nerves. However, there are a number of possibilities as to the origin of these processes. They may originate from the pedal ganglia or other central ganglia and/ or from ganglionic neurons of the pedal and subepithelial plexuses, and/or sensory neurons in which the somata may be located between or beneath the epithelial cells of the integument (as described above). Moreover, in $M$. oblongus the largest proportion of the catecholamine neurons and fibers of the central nervous system are located in the pedal ganglia. A bilateral catecholamine neuronal cluster (about 50 small neurons) was detected lateral to the pedal neuropil, extending like a column from the medioventral to the mediodorsal portion of these ganglia
(19). A similar column was detected in Helix, Achatina and Limax maximus (22,26-28). In Lymnaea this column is formed by dopaminergic neurons (29), although there is no reference to its function. The presence in $M$. oblongus of a catecholaminergic nerve mesh on the pedal muscle cells and the presence of neuromuscular junctions displaying electrondense and electron lucid vesicles (20) suggest that catecholamine (probably dopamine) is involved in the neuromuscular transmission in M. oblongus.

It is known that dopamine and 5-HT act as neurotransmitters and neuromodulators in some molluscan central sensory and motor circuits $(14,17,19,30)$. Dopamine is the principal catecholamine present in several gastropods $(6,13,31)$. However, the presence of peripheral catecholamine neurons has also been reported in the foot of the gastropod Lymnaea stagnalis (2) and in the pedal plexus of $M$. oblongus (present paper).

In M. oblongus, the large branches of the pedal nerves, the neurons and fibers of both the pedal and subepithelial plexuses, the peripheral neuronal processes between the epithelial cells of the integument and the varicose fibers on the pedal muscle exhibited 5HT immunoreactive. Similarly, the large 5HT immunoreactive fibers may also have a number of origins, including the pedal ganglia and/or the pedal and subepithelial plexuses as well as sensory neurons. The greatest number of serotonergic neurons in the central nervous system was found in the pedal ganglion of $M$. oblongus. The largest positive neuronal cluster of each pedal ganglion is distributed along the median edge (19). A similar distribution of 5-HT neuronal clusters has been identified in Lymnaea, Achatina, Limax maximus, $H$. aspersa, and H. pomatia $(22,26,28,32,33)$. The $5-\mathrm{HT}$ immunoreactive fibers of the pedal nerves, pedal plexus and varicosities on the pedal muscle cells of $M$. oblongus may originate from 5-HT immunoreactive neurons of the pedal ganglia, as is the case with the pedal 
muscles of Pleurobranchaea californica and Tritonia diomedea (8).

There is a considerable body of evidence suggesting that 5-HT synthesized in the pedal ganglionic neurons is involved in gastropod locomotion (14). The 5-HT innervation of the pedal muscle in $M$. oblongus probably indicates a modulatory function as in Aplysia brasiliana (34), Clione (35), Tritonia, and Pleurobranchaea (8). Few studies about the locomotion of land snails are available (16). The 5-HT fibers of the pedal nerve branches of $M$. oblongus continued into the pedal plexus, divided and penetrated the ganglionic neuropil, sometimes emitting collateral fibers, or giving origin to labeled varicosities that entered the cortical region and surrounded negative neuronal somata or continued to other nerves of the plexus. In an ultrastructural study of the same ganglia of M. oblongus, the neuronal processes located in the neuropil showed different types of synaptic vesicles and electron-dense vesicles in the nerve terminals of neuromuscular junctions $(3,20)$. Thus, taking these findings into account we can surmise that 5-HT fibers arising from the pedal ganglia form the pedal plexus and may modulate the intrinsic neurons. Moreover, the production of waves of muscular contraction after 5,7-DHT administration in the pedal musculature (19) suggests the involvement of 5-HT in the locomotion of M. oblongus.

In the subepithelial region, 5-HT fibers form a delicate mesh beneath the epithelial cells. Such fibers have also been detected in Tritonia, Pleurobranchaea and Lymnaea $(8,36)$. In Lymnaea, the 5-HT varicosities found in this region arise from neurons located in the pedal ganglia and contact the mucus cells of the integument (36). The ciliated epithelial cells of the foot are involved in locomotion in several aquatic gastropods such as Tritonia diomedea, Planorbis and Lymnaea and some of the smaller stylommatophorans (37). In these snails, the pedal ganglia stimulate the ciliary beating and 5-HT probably acts directly upon ciliated cells, controlling the ciliary locomotion (38) and upon secretory cells, controlling mucus secretion in ciliary gliding (36). In addition, it is probable that dopamine exerts an inhibitory effect on the ciliated pedal cells (36). Though the principal means of locomotion in $M$. oblongus is the wave movement of the pedal musculature along the ventral surface of the foot, the ciliated epithelium and the 5-HT mesh may also be partially involved in the foot movement, given that the forces of the muscular waves are coupled to the substrate by a thin layer of pedal mucus (3). 5-HT injection prior to thermal aversive stimulation produced a strong increase in mucus secretion in the ventral zone of the foot of $M$. oblongus (10). This finding suggests a serotonergic involvement in the mucus secretion of the integument. At the same time, the 5HT subepithelial plexus may be involved in the modulation of the sensory information originating from the primary sensory receptors (8). The intraepithelial 5-HT distal processes in the foot epithelium of $M$. oblongus may arise from the primary sensory neurons located beneath the epithelial cells. These neurons probably send their proximal processes to the pedal ganglia via the pedal nerves.

In the foot of Tritonia and Pleurobranchaea, 5-HT neuronal somata were not identified, suggesting that all 5-HT innervation originates from the pedal ganglia (8). Nevertheless, 5-HT neurons were detected in the peripheral nervous system and branchial plexus of Aplysia (39), in the foot of Lymax (8), and in the pedal plexus and beneath the epithelial cells of $M$. oblongus. These findings suggest that subepithelial innervation may also originate from the peripheral neuronal bodies and not only from the central nervous system neurons.

Our working hypothesis is that 5-HT and catecholamines play a role in controlling the locomotion or other movements associated with aversive behavior in the land snail $M$. oblongus, and the data presented here are consistent with it. 


\section{References}

1. Bullock TH \& Horridge $G$ (1965). Structure and Function in the Nervous System of Invertebrates. Freeman \& Co., San Francisco, CA, USA, 2

2. Croll RP, Voronezhskaya EE, Hiripi L \& Elekes K (1999). Development of catecholaminergic neurons in the pond snail, Lymnaea stagnalis: II. Postembryonic development of central and peripheral cells. Journal of Comparative Neurology, 404: 297-309.

3. Faccioni-Heuser MC (1999). Aspectos histofisiológicos da musculatura e do plexo pedioso do caracol pulmonado Megalobulimus oblongus. Doctoral thesis, Departamento de Fisiologia, Universidade Federal do Rio Grande do Sul, Porto Alegre, RS, Brazil.

4. Rogers DC (1969). Fine structure of smooth muscle and neuromuscular junctions in the foot of Helix aspersa. Zeitschrift für Zellforschung und Mikroskopische Anatomie, 99: 315-355.

5. Essawy A, Abdelmeguid $M$ \& Hassan $Y$ (1994). The ultrastructure of the neural plexus in the foot musculature of the desert snail Ereminia ehrenbergi. Functional Development and Morphology, 4: 17-19.

6. Ottaviani E, Caselgrandi E \& Franchini A (1988). Epinephrine investigation in the snail brain of Helicella virgata (Gastropoda, Pulmonata). Comparative Biochemistry and Physiology, 89C: 267-269.

7. Rigon PL, Olivera AH, Faccioni-Heuser MC, Zancan DM \& Achaval $M$ (1998). Imunorreatividade à substância $P$ no plexo pedioso do caracol terrestre Megalobulimus oblongus. Proceedings of the VII Congreso Ibero-Americano de Biología Celular, Montevideo, Uruguay, October 26-30, 1998.

8. Moroz LL, Sudlow LC, Jing J \& Gillette R (1997). Serotoninimmunoreactivity in peripheral tissues of the opisthobranch molluscs Pleurobranchaea californica and Tritonia diomedea. Journal of Comparative Neurology, 382: 176-188.

9. Straub H \& Kuhlmann D (1984). Identification and quantitative measurements of biogenic monoamines in the central nervous tissue of some gastropods. Comparative Biochemistry and Physiology, 78C: 319-323.

10. Achaval M, Penha MAP, Swarowsky A \& Zancan DM (2001). Estimulação térmica aversiva no caracol $M$. oblongus. Proceedings of the XVI Annual Meeting of the Federação de Sociedades de Biologia Experimental, Caxambu, MG, Brazil, August 29-September 1,150

11. Teyke T, Rosen SC, Weiss KR \& Kupfermann I (1993). Dopaminergic neuron B20 generates rhythmic activity in the feeding motor circuitry of Aplysia. Brain Research, 630: 226-237.

12. Yeoman MS, Kemenes G, Benjamin PR \& Elliot CJH (1994). Modulatory role for the serotonergic cerebral giant cells in the feeding system of the snail, Lymnaea. Photoinactivation. Journal of Neurophysiology, 72: 1372-1382.

13. Kabotyanski EA, Baxter DA \& Byrne JH (1998). Identification and characterization of catecholaminergic neuron B65, which initiates and modifies patterned activity in the buccal ganglia of Aplysia. Journal of Neurophysiology, 79: 605-621.

14. Bulloch AGM \& Ridway RL (1995). Comparative aspects of gastropod neurobiology. In: Breidbach O \& Kutsch W (Editors), The Nervous System of Invertebrates: An Evolutionary and Comparative Approach. Birkhäuser Verlag, Basel, Switzerland, 89-113.

15. Dyakonova TL, Elofsson R, Carlberg M \& Sakharov DA (1995). Complex avoidance behavior and its neurochemical regulation in land snail Cepaea nemoralis. General Pharmacology, 26: 773-777.

16. Balaban PM (2002). Cellular mechanisms of behavioral plasticity in terrestrial snails. Neuroscience and Biobehavioral Reviews, 26:
597-630.

17. Pavlova GA (2001). Effects of serotonin, dopamine and ergometrine on locomotion in the pulmonate mollusc Helix lucorum. Journal of Experimental Biology, 204: 1625-1633.

18. De La Torre JC \& Surgeon JW (1976). A methodological approach to rapid and sensitive monoamine histofluorescence using a modified glyoxylic acid technique: the SPG method. Histochemistry, 49: 81-93.

19. Zancan DM, Brauer M \& Achaval M (1997). Monoamine-containing neurons in the central nervous system of Megalobulimus oblongus (Gastropoda, Pulmonata). Comparative Biochemistry and Physiology, 118B: 765-772.

20. Faccioni-Heuser MC, Zancan DM, Lopes CQ \& Achaval M (1999). The pedal muscle of the land snail Megalobulimus oblongus (Gastropoda, Pulmonata): an ultrastructural approach. Acta Zoologica, 80: 325-337.

21. Salimova NB, Sakharov DA, Milosevic I, Turpaev TM \& Rakic L (1987). Monoamine-containing neurons in the Aplysia brain. Brain Research, 400: 285-299.

22. Osborne NN \& Cottrell GA (1971). Distribution of biogenic amines in the slug, Limax maximus. Zeitschrift für Zellforschung und Mikroskopische Anatomie, 112: 15-30.

23. Arvidsson U, Cullheim S, Ulfhake B, Luppi PH, Jouvet M \& Hökfelt $T$ (1994). Quantitative and qualitative aspects on the distribution of 5-HT and its coexistence with substance P and TRH in cat ventral medullary neurons. Journal of Chemical Neuroanatomy, 7: 3-12.

24. Sternberger LA (1979). Immunocytochemistry. Wiley \& Sons, Chichester, UK, 338.

25. Vitellaro-Zuccarello L, De Biasi \& Blum I (1983). Histochemical and ultrastructural study on the innervation of the byssus glands of Mytilus galloprovincialis. Cell and Tissue Research, 233: 403-413.

26. Croll CP (1988). Distribution of monoamines within the central nervous system of the juvenile pulmonate snail Achatina fulica. Brain Research, 460: 29-49.

27. Hernádi L, Juhos S \& Elekes K (1993). Distribution of tyrosine hydroxylase-immunoreactive neurons in the central nervous system of the snail Helix pomatia. Cell and Tissue Research, 274: 317326.

28. Sedden CB, Walker RJ \& Kerkut GA (1968). The localization of dopamine and $5 \mathrm{HT}$ in neurones of Helix aspersa. Symposium of the Zoological Society of London, 22: 19-32.

29. Elekes K, Kemenes G, Hiripi L, Geffard M \& Benjamin PR (1991). Dopamine-immunoreactive neurones in the central nervous system of the pond snail Lymnaea stagnalis. Journal of Comparative Neurology, 307: 214-224

30. Walker RJ \& Holden-Dye L (1989). Commentary on the evolution of transmitters, receptors and ion channels in invertebrates. Comparative Biochemistry and Physiology, 93A: 25-39.

31. Dahl E, Falck B, Mecklenburg C, Myhrberg H \& Rosengren $E$ (1966). Neuronal localization of dopamine and 5-hydroxytryptamine in some mollusca. Zeitschrift für Zellforschung und Mikroskopische Anatomie, 71: 489-498.

32. Audesirk G (1985). Amine-containing neurons in the brain of Lymnaea stagnalis: Distribution and effects of precursors. Comparative and Biochemical Physiology, 2: 359-365.

33. Hernádi L, Elekes K \& Rósza K (1989). Distribution of serotonincontaining neurons in the central nervous system of the snail Helix pomatia. Comparison of immunocytochemical and 5,6-dihydroxytryptamine labelling. Cell and Tissue Research, 257: 313-323. 
34. McPherson DR \& Blankenship JE (1991). Neural control of swimming in Aplysia brasiliana. III. Serotonergic modulatory neurons. Journal of Neurophysiology, 66: 1366-1379.

35. Satterlie RA (1995). Serotonergic modulation of swimming speed in the pteropod mollusc Clione limacina. Peripheral modulatory neurons. Journal of Experimental Biology, 1198: 905-916.

36. McKenzie JD, Caunce M, Hetherington MS \& Winlow W (1998). Serotonergic innervation of the foot of the pond snail Lymnaea stagnalis (L.). Journal of Neurocytology, 27: 459-470.

37. Trueman ER (1983). Locomotion in molluscs. In: Saleudin ASM \&
Wilbur KM (Editors), The Mollusca. Vol. 4. Academic Press, New York, 155-198.

38. Deliagina TG \& Orlovsky GN (1990). Control of locomotion in the freshwater snail Planorbis corneus. II. Differential control of various zones of ciliated epithelium. Journal of Experimental Biology, 152: 405-423.

39. Peretz B \& Estes J (1974). Histology and histochemistry of the peripheral neural plexus in the Aplysia gill. Journal of Neurobiology. 5: 3-19. 